\title{
Características da Produção Veiculada na Revista de Educação e Pesquisa em Contabilidade no Período de 2007 a 2012
}

\begin{abstract}
Resumo
O principal objetivo da ciência é a geração do conhecimento, sendo que a produção acadêmica e a disseminação dos resultados dessas pesquisas representam fatores relevantes para impulsionar a expansão do saber. Nesse panorama, este artigo teve como objetivo explorar a produção acadêmica da Revista de Educação e Pesquisa em Contabilidade de 2007 a 2012. A base teórica deste estudo baseou-se na teoria da Bibliometria, de redes sociais e de outros estudos com foco similar a este. No que tange à parte metodológica, esta pesquisa se focou nas técnicas de análise bibliométrica e de rede social, utilizando-se da estatística descritiva, em um universo de 106 artigos identificados. Identificou-se, por meio deste estudo, a predominância de artigos em parceria (cerca de 91\%), dos quais os autores que se destacaram como os mais profícuos foram Aridelmo José Campanharo Teixeira e Gilberto de Andrade Martins, sendo o primeiro autor o que apresentou maior centralidade de grau e de intermediação. A Universidade de São Paulo (USP) foi a Instituição de Ensino Superior (IES) mais produtiva, e a que se destacou nas centralidades de grau e de intermediação. Dos 106 artigos analisados, os temas mais abordados foram os seguintes: Ensino e Pesquisa, Transparência, Contabilidade Internacional, Educação Contábil, Demonstrações Contábil-Financeira, Contabilidade Gerencial, História da Contabilidade, Contabilidade Governamental, Mercado de Capitais e Controladoria.
\end{abstract}

Palavras-chaves: Revista de educação e pesquisa em contabilidade; Produção acadêmica; Bibliometria; Rede social.
Henrique César Melo Ribeiro Doutorando em Administração (UninoveSP) e Professor da Faculdade Maurício de Nassau. Contato: BR 343 Km 7,5 S/N, Floriópolis, Parnaíba, PI, Brasil, CEP: 64.202-260.

E-mail: hcmribeiro@hotmail.com 


\section{Introdução}

A publicação em periódicos científicos é fundamental para determinar uma produção acadêmica. No entanto, o que vai consolidá-la como uma importante contribuição para a evolução do conhecimento é se ela resultar no surgimento, fomento e consolidação de grupos de pesquisa em diversas áreas (Dantas, Silva, Santa \& Vieira, 2011). Nesse contexto, remete que o principal objetivo da ciência é a geração do conhecimento, sendo a produção acadêmica e a disseminação dos resultados dessas pesquisas um relevante impulsionador da expansão do saber (Dias, Barbosa Neto \& Cunha, 2011). A produção científica de uma área de conhecimento reflete o seu estado da arte e sua evolução. Nesse panorama, realça-se novamente a importância dos periódicos que possuem uma função de destaque no que diz respeito à qualidade da pesquisa que, por sua vez, contribuirá para o avanço do conhecimento (Meli \& Oliveira Neto, 2011).

Nesse contexto, salienta-se que a Ciência Contábil no Brasil vem se desenvolvendo ao longo dos anos e sendo fortalecida com o empenho dos autores que buscam analisar e desvendar os problemas e fenômenos que ocorrem nessa área (Meli \& Oliveira Neto, 2011). Nesse aspecto, as técnicas de análise da Bibliometria e de Redes Sociais são essenciais para melhor entender os fenômenos e as características da produção científica veiculada na área de Contabilidade no Brasil (Meli \& Oliveira Neto, 2011).

No que tange aos periódicos acadêmicos da área de Contabilidade, destaca-se a Revista de Educação e Pesquisa em Contabilidade (REPeC), que, na nova classificação pelo Sistema Qualis da Capes (20102012), divulgada em 2013, foi classificada como B2 na área de avaliação Administração, Ciências Contábeis e Turismo (CAPES, 2013; REPeC, 2013). Essa publicação teve início em 2007 e até 2012, já havia publicado 106 artigos. Essa revista tem como missão divulgar a produção de conhecimento na área contábil e como objetivo difundir o conhecimento contábil construído (REPeC, 2013).

O propósito deste trabalho é explorar o que tem sido pesquisado e publicado na REPeC, por meio das análises bibliométrica e de rede social. Tal propósito justifica-se, pois o papel da academia é criar e disseminar conhecimento na sociedade, sendo a produção acadêmica a origem do ensino e da extensão (Rowe \& Bastos, 2010). Daí a importância dos periódicos tanto para a comunicação científica quanto para a avaliação dos pesquisadores (Oliveira, 2002).

Ressalta-se que a bibliometria é uma ferramenta de análise que explora publicações em livros, relatórios e em revistas acadêmicas (Ferreira, 2011). Essa pesquisa focou-se na observação e nas técnicas bibliométricas (Ramos-Rodríguez\& Ruíz-Navarro, 2004), bem como na análise de redes sociais para avaliar a estrutura de relacionamento entre os autores (Nerur, Rasheed \& Natarajan, 2008), as IES (Francisco, 2011) e entre autores e IES simultaneamente, configurando assim uma rede two-mode (Guarido Filho \& Machado-da-Silva, 2010).

Alguns estudos similares ao que se propõe a fazer neste estudo já foram realizados, ou seja, trabalhos que tiveram o objetivo de investigar, mapear, explorar e/ou analisar especificamente periódicos acadêmicos da área de Contabilidade. São eles: Leite Filho e Siqueira (2007), Barbosa, Echternacht, Ferreira e Lucena (2008), Batistella, Bonacim e Martins (2008), Espejo, Cruz, Lourenço, Antonovz \& Almeida (2009), Perdigão, Niyama e Santana (2010), Brunozi Júnior et al. (2011), Dantas et al. (2011), Ribeiro (2012) e Souza, Silva, Araújo e Silva (2012). Essas pesquisas mostram que aprender o estágio da produção acadêmica da área contábil em periódicos nacionais é preponderante para o fomento da área (Batistella, Bonacim \& Martins, 2008).

Diante disso, evidencia-se a questão de pesquisa que norteou este estudo: Qual é o perfil da produção acadêmica da Revista de Educação e Pesquisa em Contabilidade de 2007 a 2012 ? Com base nesse questionamento, o objetivo volta-se para a exploração da produção acadêmica da Revista de Educação e Pesquisa em Contabilidade de 2007 a 2012. Este trabalho justifica-se por entender que mapear e conhecer trabalhos acadêmicos publicados em determinada área por meio de revisões sistemáticas é uma das maneiras de possibilitar a avaliação e a reflexão dessas publicações e da área em questão (Cardoso, Neto, Riccio \& Sakata, 2005). Em razão disso, este estudo contribuirá para o desenvolvimento e a evidenciação da pesquisa científica em Ciências Contábeis no Brasil (Silva \& Ott, 2012), pois, a partir dos estudos pu- 
blicados na revista $\mathrm{REPeC}$ realizados por pesquisadores, poderá levar a questionamentos, sobretudo nos temas abordados aqui, contribuindo para o fomento das pesquisas na área ora em investigação.

\section{Bibliometria, Rede Social e Pesquisas em Periódicos de Contabilidade}

A bibliometria desenvolveu-se mediante a elaboração de leis empíricas sobre o comportamento da literatura (Egghe, 2005), as quais são mais utilizadas em trabalhos desse escopo. São elas: a Lei de Bradford, que enfatiza a produtividade dos periódicos e, portanto, o grau de relevância da revista, que é um aspecto bastante importante; a Lei de Lotka, que destaca a produtividade científica de autores, ou seja, o número de vezes que cada autor aparece citado em outros trabalhos científicos, por meio de um modelo de distribuição de tamanho-frequência em um conjunto de pesquisas, evidenciando aspectos de coautoria; e a Lei de Zipf, que conta as incidências de palavras que aparecem nos artigos científicos, como, por exemplo, as palavras-chaves mais visualizadas nos artigos investigados.

Complementando a investigação bibliométrica, também foi utilizado neste trabalho um monitoramento das redes de coautoria (Ramos-Rodríguez \& Ruíz-Navarro, 2004) a fim de compreender as ligações e conectividades entre autores e suas respectivas IES. O conceito de redes pode auxiliar na compreensão dos processos de interação social entre os atores e da própria geração do conhecimento. Nesse sentido, redes são um conjunto de nós e suas relações proporcionam interações e organizações sociais em que a informação e o conhecimento são elementos-chave desse processo (Didriksson, 2003).

Também se pode entender a rede social como um conjunto de pessoas, instituições ou organizações que, por possuírem afinidades em comum, compartilham, por exemplo, trabalho e/ou informações e, por meio dessas ligações, constroem e reconstroem uma estrutura social (Tomaél \& Marteleto, 2006). Sebastián (1999, p. 309) aprofunda esse conceito, trazendo-o para o campo da pesquisa científica como "[...] modalidade de redes de cooperação e [que] se definem pela associação de grupos de pesquisa para a realização de trabalhos conjuntos, geralmente através de projetos de Pesquisa e Desenvolvimento".

Para se analisar uma rede social, é necessária a compreensão da sua estrutura, assim como das relações que a compõe. A principal propriedade estrutural da rede é a densidade que, segundo Gnyawali e Madhavan (2001), pode ser entendida por meio da extensão da interconexão entre os atores, ou seja, quanto maior a interconexão maior a densidade. Tratando-se das relações, a coesão entre os atores é o indicador mais representativo. As medidas de centralidade e densidade (Cruz, Espejo, Costa \& Almeida, 2011) compõem algumas das principais propriedades estruturais de uma rede.

Entre as centralidades, destacam-se a centralidade de grau (Degree), a centralidade de proximidade (Closeness) e a centralidade de intermediação (Betweenness) (Meli \& Oliveira Neto, 2011). A centralidade de grau é definida pelo número de laços adjacentes de um ator com relação aos outros em uma rede (Wasserman \& Faust, 1994), possibilitando uma avaliação da atividade local dos atores. A centralidade de proximidade (Closeness) é função da proximidade ou distância de um ator em relação a todos os outros em uma rede. A ideia percebida na análise desse indicador é que um autor com elevada centralidade de aproximação é aquele que possui maiores condições de interagir rapidamente com todos os outros (Hanneman \& Riddle, 2005; Scott, 2000; Wasserman \& Faust, 1994).

A centralidade de intermediação (Betweenness) avalia a dependência de atores não adjacentes de outros que atuam como uma espécie de ponte para efetivação da interação deles (Freeman, 1992). Nesse caso, quanto maior o grau de centralidade de intermediação maior a probabilidade de controle de um ator sobre outros que dele dependem para executar a interação. Redes de conhecimento, assim como a maioria das redes sociais, têm na coesão um dos seus principais elementos de análise. Assim, no comportamento coletivo dos atores de um mesmo grupo, a coesão serve de base para solidariedade e identidade do grupo.

A revisão da literatura identificou alguns trabalhos bibliométricos e/ou de rede social já realizados especificamente em revistas, ou seja, que já exploraram acervos de periódicos especificamente da área contábil. 
Leite Filho e Siqueira (2007) descreveram e analisaram as principais características bibliométricas da Revista Contabilidade \& Finanças (USP) no período de 1999 a 2006. Os resultados identificados pelos autores apontaram que no período supracitado houve predominância de autoria de gênero masculino; a colaboração entre dois autores (47\%) foi a forma mais frequente de autoria entre os trabalhos escritos; $76 \%$ dos autores tiveram apenas uma contribuição no periódico; nas referências bibliográficas, os autores enfatizaram livros (40\%); seguidos de artigos periódicos (23\%), foram encontrados indícios de endogenia com a maioria dos autores vinculados à USP. E os testes estatísticos sugeriram que a distribuição de autoria seguiu padrões da teoria Bibliométrica (Lei de Lotka).

Barbosa et al. (2008) analisaram os artigos da Revista Brasileira de Contabilidade do período de 2003 a 2006, por meio de uma aplicação bibliométrica. Verificaram um declínio do número de trabalhos publicados, além de uma constante publicação de artigos com uma única autoria. Destacaram-se a presença de $72 \%$ de homens como autores, bem como a presença de $35 \%$ de articulistas com título de Mestre. A análise das referências permitiu verificar uma pequena consulta a fontes internacionais e que a quantidade de fontes consultadas vem aumentando durante o período analisado. Por fim, os pesquisadores constataram que muito se tem a discutir para ter a RBC em destaque na academia contábil.

Batistella et al. (2008) apreenderam o estágio da produção acadêmica na área contábil por meio do mapeamento de dois periódicos: Contabilidade \& Finanças (FEA-USP) e Revista Base (Unisinos). Os resultados observados pelos pesquisadores sugeriram que a Revista Contabilidade \& Finanças (FEA-USP) apresenta, com relação ao quesito "forma", um desempenho geral categorizado como "bom", enquanto a Revista Base (Unisinos) apresenta um desempenho "mediano". Observou-se também uma maior concentração de autores nas publicações da Revista Contabilidade \& Finanças (FEA-USP) (recorrência) em relação à Revista Base (Unisinos). O autor Otávio Ribeiro de Medeiros foi o que mais publicou na Revista Contabilidade \& Finanças e a autora Ilse Maria Beuren se destacou na revista Base.

Espejo, Cruz, Lourenço et al. (2009) analisaram as tendências temáticas e metodológicas de publicações veiculadas na Accounting, Organizations \& Society (AOS), na Revista Contabilidade \& Finanças (RCF) e na The Accounting Review (TAR) entre 2003 e 2007. Os resultados obtidos pelos autores sugeriram predominância da temática de usuários externos. Nos periódicos AOS e na TAR, a temática relativa aos usuários internos apresentou tendência de crescimento. Perceberam maiores ocorrências de abordagem da racionalidade econômica, todavia, com tendência de queda. As abordagens de pesquisa comportamental e institucional mostraram-se ascendentes. Os autores mais produtivos foram responsáveis por $14,1 \% \mathrm{da}$ produção científica analisada. Apenas 2,6\% dos autores obtiveram publicação em mais de um periódico.

Perdigão, Niyama e Santana (2010) analisaram as características da revista Contabilidade, Gestão e Governança, no período de 1998 a 2009. Os autores verificaram o predomínio de autoria em parceria; a diversidade de origem dos autores; a média de referências por artigo, que foi de 22,05 citações; e o tema Contabilidade Gerencial, que se destacou nas pesquisas analisadas. Os autores ainda evidenciam os seguintes temas: Contabilidade Internacional, que remete para a harmonização das normas contábeis; Contabilidade Social e Ambiental; Contabilidade Tributária; e a Governança Corporativa.

Brunozi Júnior et al. (2011) analisaram a distribuição, as características metodológicas, a evolução e a temática das publicações científicas no periódico Revista de Contabilidade \& Finanças da USP, de 1989 a 2009. A avaliação da revista indicou a concentração de autores afiliados à USP, principalmente docentes doutores, entretanto, a partir de 2003, os autores observaram a participação de outras entidades nas publicações. O periódico apresentou evolução ao longo dos anos, sendo que se percebe a distinção das temáticas propostas nos artigos. Nesse contexto, verifica-se a predominância de estudos relacionados a Finanças e Contabilidade (29\%); Ensino de Contabilidade e Conhecimento (13\%); Contabilidade Clássica e Teoria da Contabilidade (12\%); e Sistemas de Informação, Comunicação e Evidenciação (11\%). Quando se considera a proposta metodológica diversificada dos estudos, observa-se, quanto aos fins, a endogenia de trabalhos descritivos, principalmente no que concerne aos primeiros anos da revista. Quanto aos meios, notou-se, entre 1989 e 2002, uma concentração de publicações de cunho bibliográfico e documental. O cenário é distinto entre 2003 e 2009, quando predominaram estudos empíricos. 
Dantas et al. (2011) avaliaram a evolução do padrão da produção científica contábil no Brasil e nos Estados Unidos, entre 2001 e 2008, utilizando-se, para isso, dos benchmarks das revistas: Revista de Contabilidade e Finanças (RCF) e a The Accounting Review (TAR). Os testes trabalhados pelos autores revelaram que para a maior parte dos parâmetros analisados não foram confirmadas as premissas de que as características da produção da RCF são equivalentes às da TAR ou evoluíram significativamente entre 2001 e 2008, aproximando-se dos parâmetros do periódico estadunidense. Dantas et al. (2011) realçam que os pesquisadores contábeis brasileiros precisam compreender algumas questões que focam que o nosso padrão de comunicação científica não está de acordo com o padrão internacional. Isso pode auxiliar a explicar o fato de que a produção contábil nacional tem pouca (quase nenhuma) inserção em periódicos internacionais.

Ribeiro (2012) investigou a produção científica do periódico Brazilian Business Review no período de 2004 a 2011. Os principais resultados identificados pelo autor foram: predominância de artigos em parceria; os autores Valcemiro Nossa, Ariovaldo dos Santos e Otávio Ribeiro de Medeiros são os mais prolíferos; Lopes, A. B. e Porter, M. E. foram os pesquisadores mais citados; e a Universidade de São Paulo foi a IES que mais publicou artigos. Constatou-se uma centralidade de rede tanto na coautoria como também nas IES. E as temáticas mais evidenciadas em 8 anos de análise foram: Finanças, Mercado de Capitais, Marketing, Organização e Negócios e Contabilidade e Auditoria. Concluiu que, mesmo sendo uma revista nova na academia, a Brazilian Business Review, por meio de seu acervo, já retrata o universo da produção científica.

Souza et al. (2012) analisaram as características dos artigos publicados na Revista de Contabilidade do Mestrado em Ciências Contábeis da Universidade do Estado do Rio de Janeiro (UERJ), no período de 2003 a 2011. Os autores contemplaram os seguintes resultados: 115 artigos foram publicados no período analisado e existiu o predomínio de autores professores doutores do sexo masculino. Além disso, observaram que a UERJ e a Universidade Federal de Santa Catarina (UFSC) foram as instituições que apresentaram o maior número de autores com artigos publicados, e que o autor com o maior número de publicações na revista foi Vicente M. Ripoll Feliu. Constataram ainda que existe o predomínio de artigos com natureza qualitativa, com referências brasileiras e que os principais temas dos artigos são: Contabilidade Gerencial e Contabilidade Financeira. Observaram também que os autores desse periódico costumam realizar produções científicas com grande número de parcerias, fato que sugere que os artigos são resultados de um compartilhamento de experiências entre os autores e que as publicações de autores com titulação inferior ao doutorado não têm ganhado espaço nesse periódico.

Portanto, são cada vez mais comuns estudos utilizando técnicas bibliométricas para analisar periódicos (Francisco, 2011). A REPeC abordou tais técnicas de análise recentemente, por meio de alguns estudos: Martins (2007), Demuner, Dias, Silva e Pelissari (2008), Olak, Slomski e Alves (2008), Espejo, Cruz, Walter, \& Gassner (2009), Coelho, Soutes e Martins (2010), Cabral, Siqueira e Siqueira-Batista (2011) e Freitas, Pacheco, Karolkievicz \& Sillas (2012). Porém, não existem ainda estudos sobre o que tem sido pesquisado e publicado na própria REPeC. Sendo assim, este é o objetivo principal deste trabalho.

\section{Procedimentos Metodológicos}

Esta pesquisa teve como objetivo explorar a produção acadêmica da Revista de Educação e Pesquisa em Contabilidade de 2007 a 2012. Para tanto, utilizou-se a técnica de análise da bibliometria, pois fornece ferramentas para mensurar as publicações científicas, que incluem livros, anais de conferências e artigos em revistas científicas (Moreira, Riccio \& Sakata, 2007).

A bibliometria, portanto, é uma ferramenta de análise que estuda publicações em livros, relatórios e em artigos (Ferreira, 2011) para quantificar, analisar e avaliar a produção intelectual científica (Ramos-Rodríguez \& Ruíz-Navarro, 2004), sintetizando-a (Chambers, 2004), sendo adequada ao objetivo deste estudo. Justifica-se o uso da análise bibliométrica por ela conseguir cobrir um período prolongado de 
tempo, ajudando assim a identificar informações importantes em Journals acadêmicos (Nerur, Rasheed \& Natarajan, 2008), como o agrupamento bibliográfico e a análise das palavras-chaves (Francisco, 2011).

Além da bibliometria, os procedimentos realizados envolveram também o exame das análises de rede, mais especificamente de coautorias (Ramos-Rodríguez \& Ruíz-Navarro, 2004; Nerur, Rasheed \& Natarajan, 2008) e de IES (Gonzalo, O. M., Hernández, A; Hernández C. \& Mendes, C., 2009; Francisco, 2011), para a melhor compreensão de suas respectivas conectividades. A análise de redes sociais é utilizada para estudar como os laços sociais entre os atores de determinada rede poderão afetar o desempenho de uma entidade (Balestrin, Verschoore \& Reyes Junior, 2010).

Sendo assim, tal procedimento é justificado por entender que o conhecimento científico é construído socialmente (Rossoni, Hocayen-da-Silva \& Júnior, 2008; Guarido Filho, Machado-da-Silva \& Gonçalves, 2009), influenciado pelos pesquisadores e seus pares, que compõem estruturalmente a rede de relações entre as IES (Rossoni, Hocayen-da-Silva \& Júnior, 2008).

Este estudo caracteriza-se por ser uma pesquisa descritiva, por apresentar a observação, classificação, análise e interpretação dos 106 artigos da REPeC. A abordagem quantitativa deve-se ao emprego da quantificação no tratamento dos dados, por meio de técnicas estatísticas descritivas (Richardson \& Peres, 1989).

A coleta de dados se desenvolveu por meio de pesquisa documental, que se justifica por selecionar, organizar, tratar e interpretar informações que se encontravam em estado bruto e dispersas (Beuren \& Longaray, 2003). A pesquisa documental buscou informações de todos os artigos, por meio do site http:// www.repec.org.br/index.php/repec/issue/archive da Revista de Educação e Pesquisa em Contabilidade.

O universo da pesquisa foi composto por 106 artigos (Figura 1) publicados no período 2007-2012. Foi realizada a marcação de todos os 106 artigos. Tal marcação consistiu na identificação dos elementos que compõem o artigo (palavras-chave, autoria, IES, corpo principal) e que ajudaram a responder à questão de pesquisa deste estudo. Logo em seguida, foi construída uma estrutura de tabelas e matrizes para melhor mensurar os indicadores deste estudo.

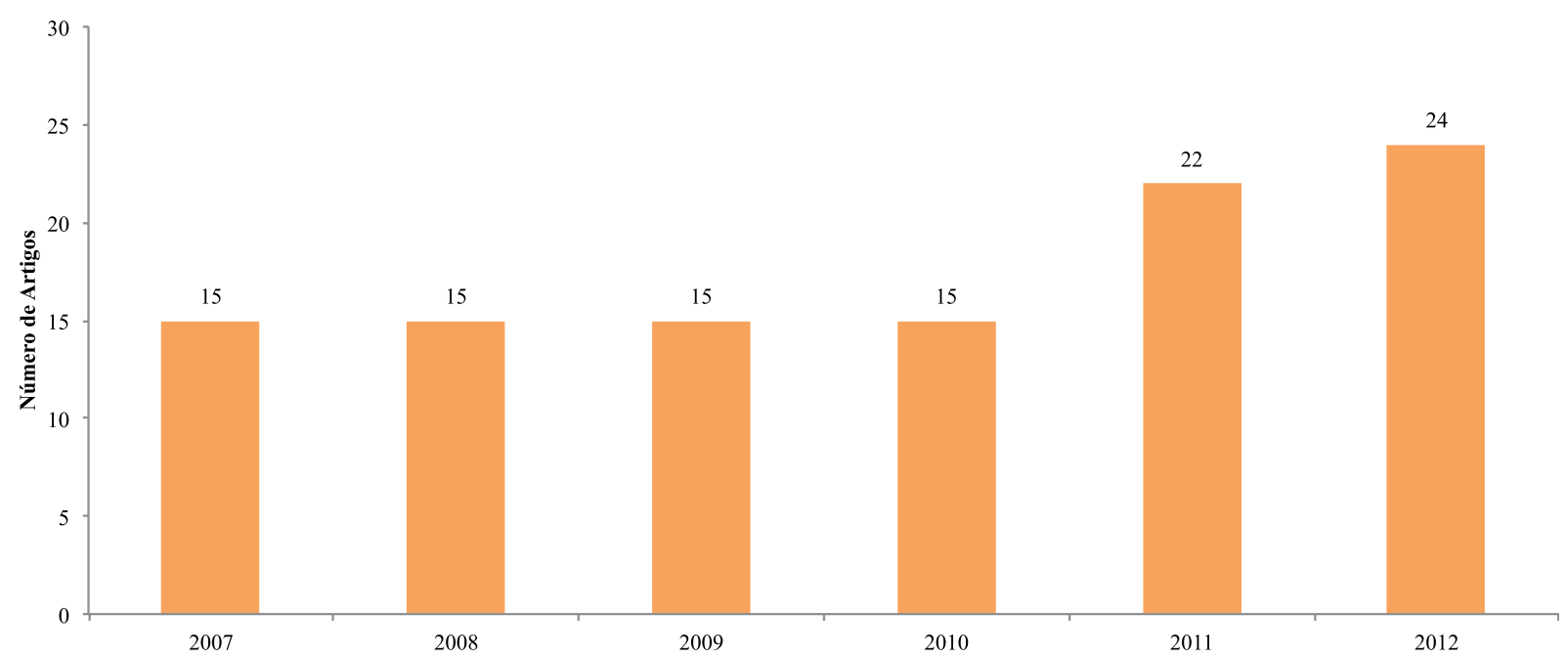

Figura 1. Artigos publicados na REPeC de 2007 a 2012

Fonte: Dados da pesquisa

Com isso, foi realizada a análise dos seguintes indicadores: (I) características de autoria; (II) autores com maior produção; (III) IES com maior produção; (IV) redes de coautoria; (V) rede social das IES; (VI) frequência das palavras-chave; (VII) temas abordados; e (VIII) abordagens e métodos de pesquisa. Tais indicadores foram calculados e capturadas, utilizando os softwares UCINET 6 for Windows, Microsoft Excel 2007 e Wordle.net, sendo este último para calcular a frequência das palavras-chaves. 


\section{Análise e Discussão dos Resultados}

A finalidade deste capítulo foi mobilizar a análise bibliométrica e de rede social dos 106 artigos publicados na REPeC.

\subsection{Características de autoria}

A Figura 2 mostra as características de autoria dos 106 artigos identificados na REPeC.

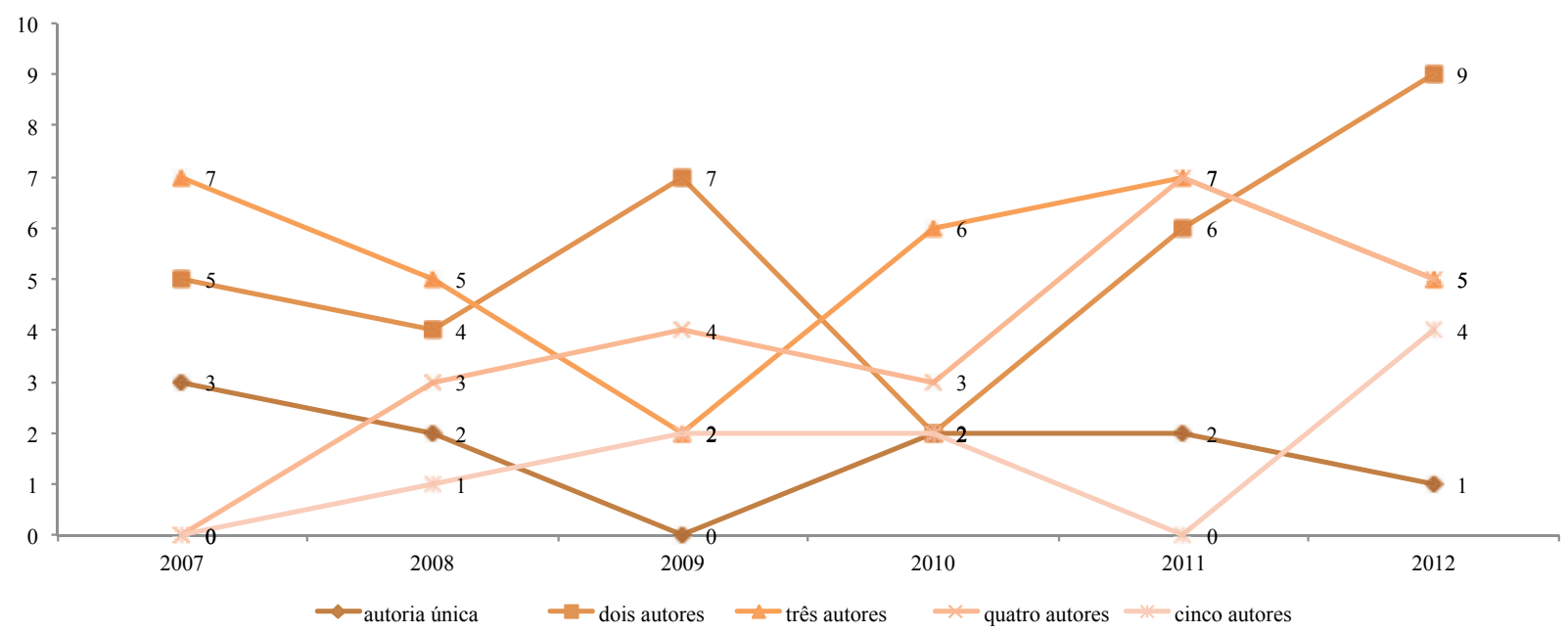

Figura 2. Autoria dos artigos

Fonte: Dados da pesquisa

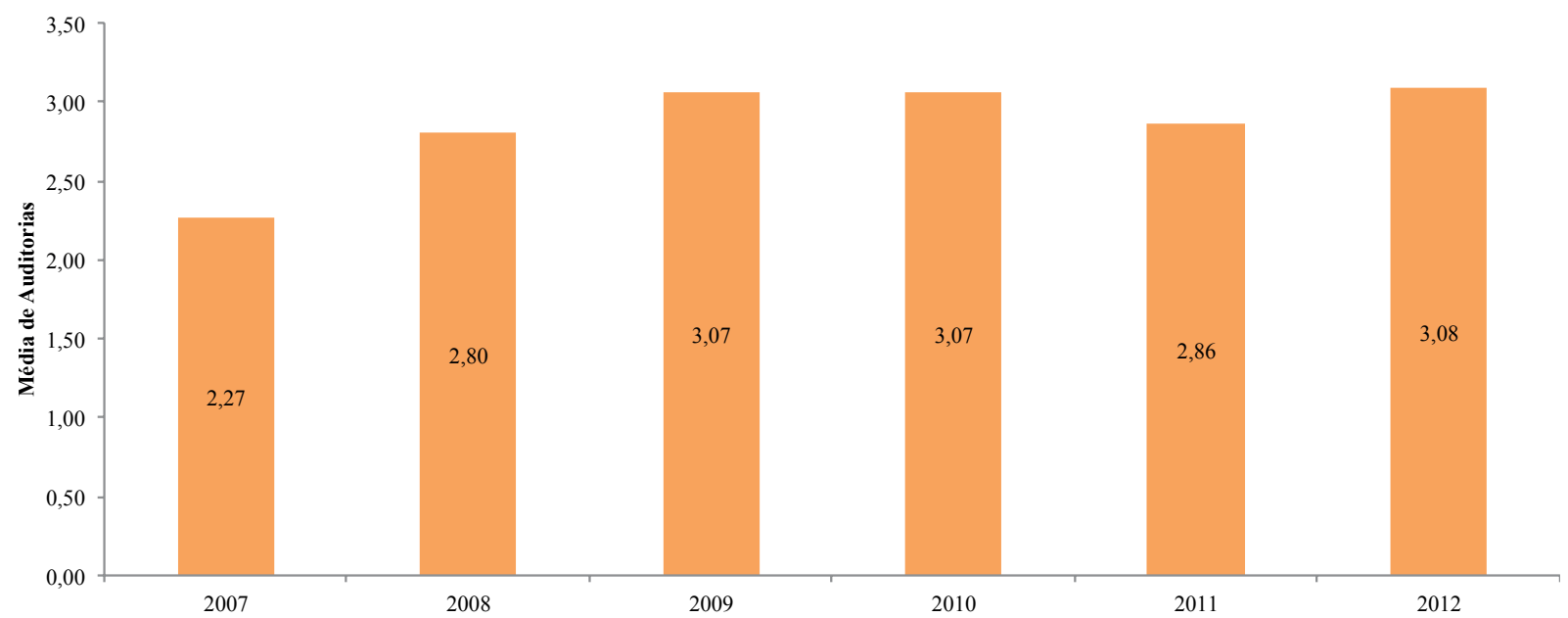

Figura 3. Média de autoria

Fonte: Dados da pesquisa 
Ao se analisar a Figura 2, observa-se que 90,57\% das publicações foram em parceria, sendo que, entre elas, as predominantes foram com dois e três autores (31,13\% e 30,19\% concomitantemente). A Figura 3 corrobora os dados da Figura 2 ao evidenciar uma crescente no que tange a média de autoria por artigo, conseguindo seu pico no ano de 2012, com 3,08 pesquisadores por artigo. Nesse panorama, remete as pesquisas similares de Leite Filho e Siqueira (2007), Ribeiro (2012) e Souza et al. (2012), nas quais os autores perceberam também a predominância de parceria entre os articulistas em seus respectivos estudos.

\subsection{Autores com maior produção}

A Figura 4 evidencia os autores mais profícuos em seis anos de estudo na REPeC.

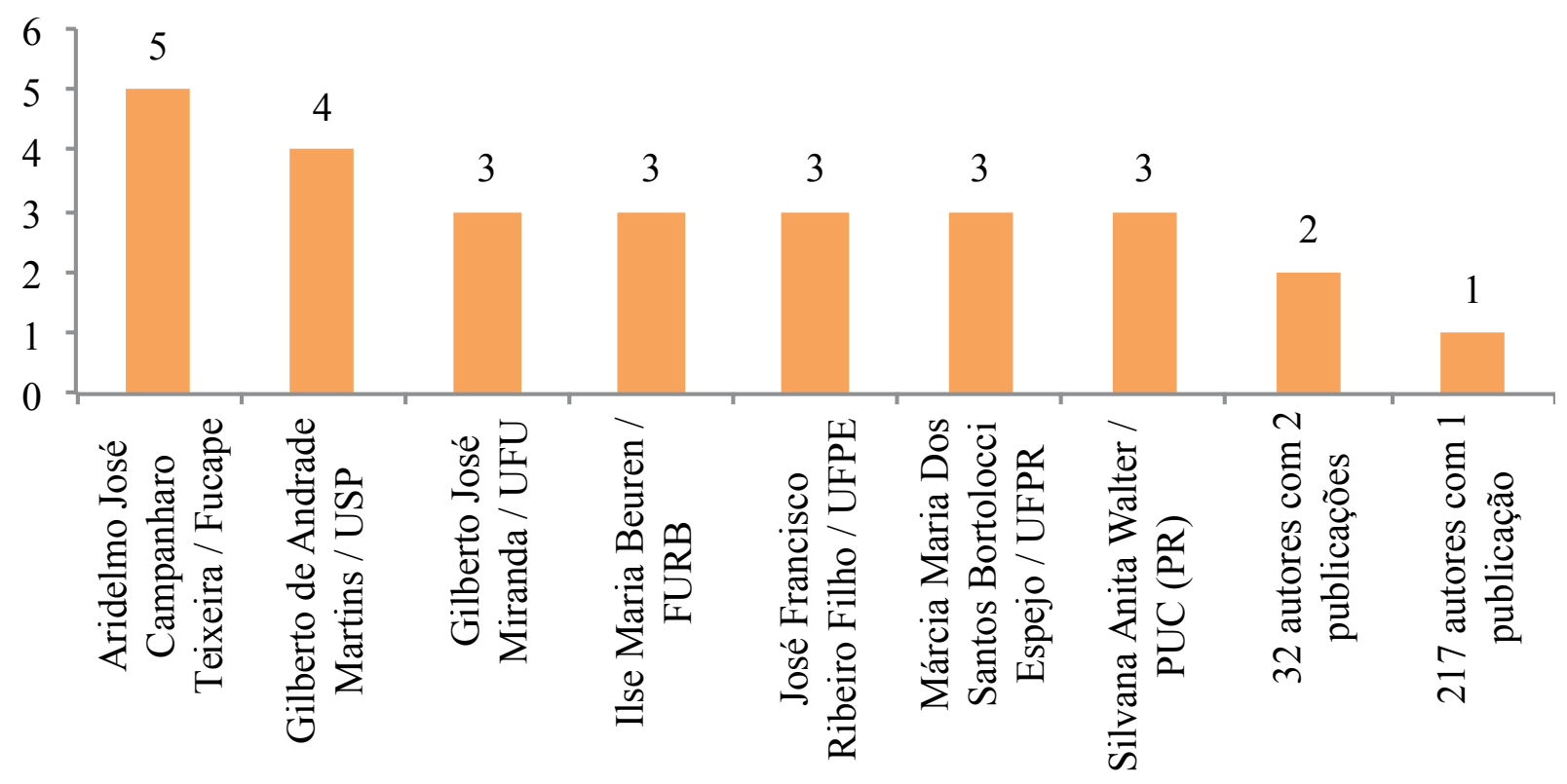

Figura 4. Autores com maior produção

Fonte: Dados da pesquisa

A Figura 4 destaca o autor Aridelmo José Campanharo Teixeira como o pesquisador que mais publicou na REPeC, com cinco artigos publicados. Em seguida, é evidenciado também o autor Gilberto de Andrade Martins, pois, em seis anos de estudo nessa revista, publicou quatro vezes. E com três publicações aparecem os articulistas Gilberto José Miranda, Ilse Maria Beuren, José Francisco Ribeiro Filho, Márcia Maria dos Santos Bortolocci Espejo e Silvana Anita Walter.

Ainda analisando a Figura 4, salienta-se que 32 articulistas publicaram 2 artigos, e a grande maioria, ou seja, 217 autores, publicou apenas uma vez, o que equivale a 84,77\%, isto é, 15,23\% dos autores publicaram mais de um artigo. Tal resultado vai ao encontro do estudo de Espejo, Cruz, Lourenço et al. (2009), os quais observaram que os autores mais produtivos em sua pesquisa foram responsáveis por $14,1 \%$ da produção acadêmica analisada. Fato similar foi observado na pesquisa de Leite Filho e Siqueira (2007), os quais constataram que $76 \%$ dos autores publicaram apenas uma vez. É relevante aqui mencionar a Lei de Lotka, que evidencia a produtividade científica de autores, ou seja, poucos publicam muito e muitos publicam pouco (Egghe, 2005). 


\subsection{IES com maior produção}

A Figura 5 dá realce às 11 IES mais produtivas em seis anos de estudo na REPeC.

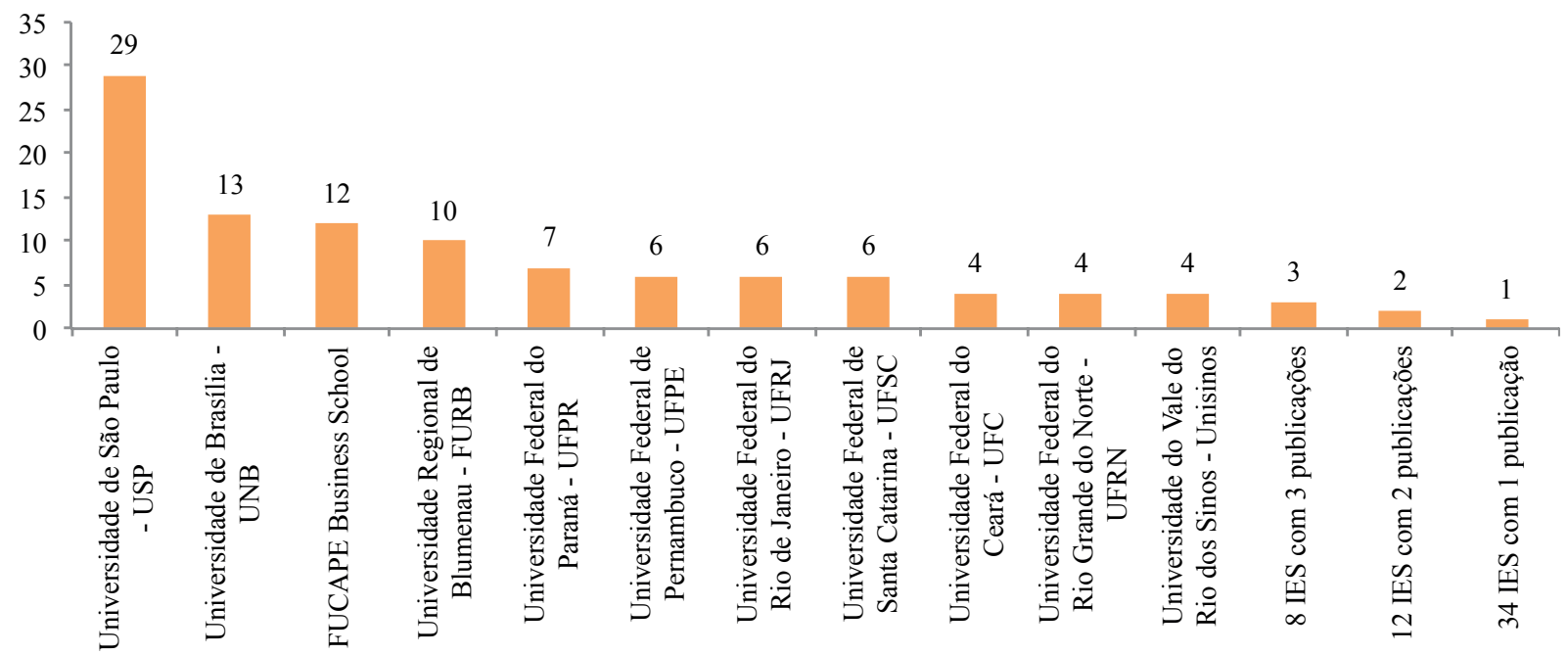

Figura 5. IES com maior produção

Fonte: Dados da pesquisa

Verificando a Figura 5, observa-se que a Universidade de São Paulo foi a IES mais profícua neste estudo, com 29 manuscritos publicados. Em seguida, ressalta-se a Universidade de Brasília, com 13 publicações. Nesse cenário, salientam-se os trabalhos de Leite Filho e Siqueira (2007), Brunozi Júnior et al. (2011), Ribeiro (2012) e Souza et al. (2012), que dão destaque também à USP como a IES mais produtiva em seus respectivos estudos.

Outras IES são destacadas na Figura 5: a FUCAPE Business School (que publicou 12 artigos); a Universidade Regional de Blumenau (FURB), com 10 papers publicados; a Universidade Federal do Paraná (UFPR) (sete publicações); a Universidade Federal de Pernambuco (UFPE), Universidade Federal do Rio de Janeiro (UFRJ) e a Universidade Federal de Santa Catarina (UFSC), todas com seis publicações cada uma; e as Universidades Federal do Ceará (UFC), Federal do Rio Grande do Norte (UFRN) e do Vale do Rio dos Sinos (Unisinos), todas com quatro papers publicados cada uma. Tais informações vão ao encontro do que foi mostrado na Figura 4, pois, dos sete autores que mais publicaram, cinco representam as IES mais profícuas: USP, FUCAPE, FURB, UFPR e UFPE.

Ainda analisando-se a Figura 5, nota-se que das 11 IES mais profícuas quatro são da região Sul (FURB, UFPR, UFSC e Unisinos), três são da região Sudeste (USP, FUCAPE e UFRJ), três da região Nordeste (UFPE, UFC e UFRN) e uma da região Centro-Oeste (UnB).

Em suma, 31 instituições publicaram de 2 a 29 artigos e 34 IES publicaram apenas uma vez, equivalendo a $52,31 \%$. 


\subsection{Redes de coautoria}

Partindo da premissa de que o conhecimento científico é desenvolvido de forma social, por meio da colaboração entre os atores envolvidos no processo (Freitas et al., 2012), as Figuras 6 e 7 visualizam as rede de coautoria dos 256 autores envolvidos em seis anos de pesquisa, sendo que a Figura 6 contempla a rede de coautoria com a centralidade de grau e a Figura 7, a rede de coautoria com a centralidade de intermediação.

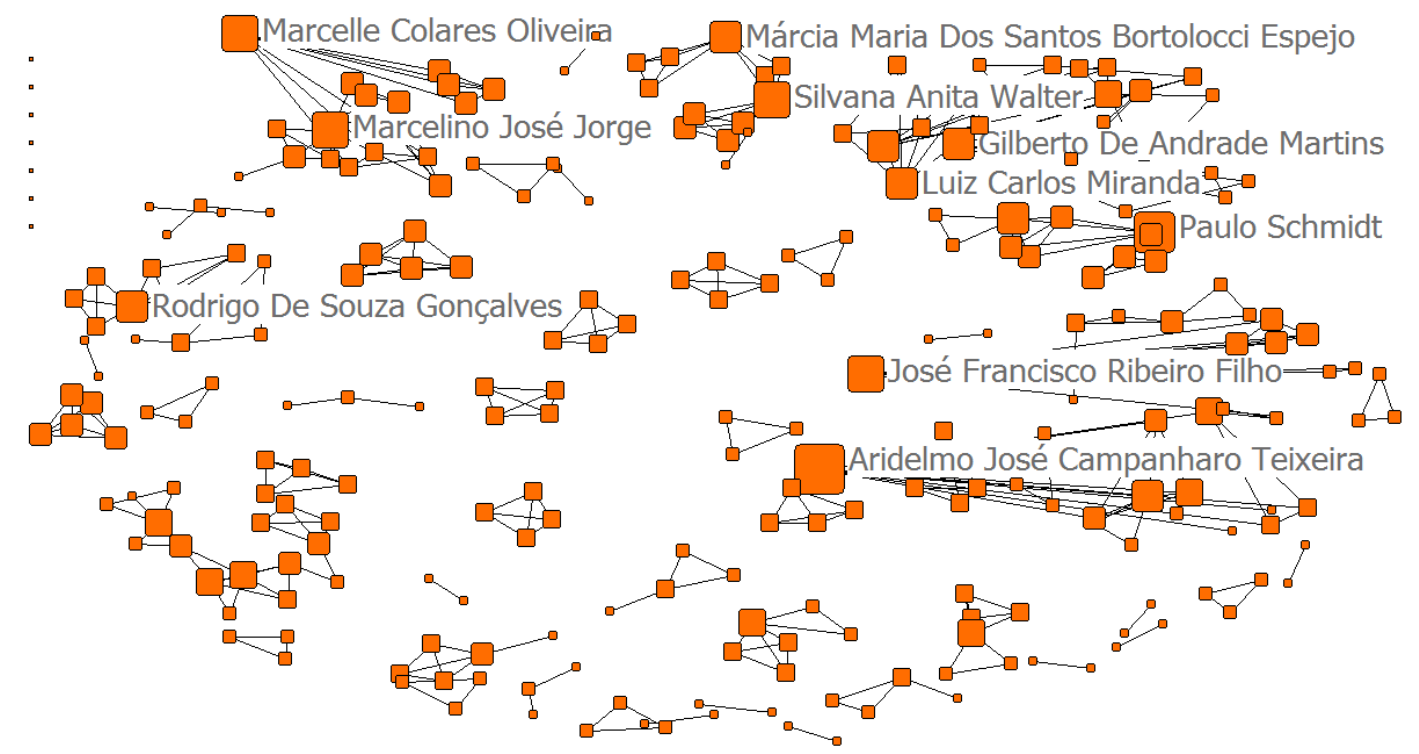

Figura 6. Rede de coautoria (degree)

Fonte: Dados da pesquisa

Verifica-se pela Figura 6 que a rede social dos autores configura-se com baixa interação, isto é, revela baixa centralização. Esse resultado pode ser corroborado quando se constata que a densidade total do grupo é de 0,0108 , ou seja, a rede realiza 1,08\% do total de suas relações. Tal cenário não reflete o ideal quando se trata de redes de coautoria, já que os grupos encontram-se isolados, não existindo atores fazendo a ponte entre eles. Esses atores seriam responsáveis pela troca de conhecimento não redundante entre os grupos. Os estudos de Francisco (2011) e Ribeiro (2012) sobre redes de coautoria corroboram as informações visualizadas na Figura 6, pois observaram, em seus respectivos estudos, pouca interação entre os atores envolvidos nos trabalhos.

Ao se analisarem os autores que se destacam na rede da Figura 6, percebe-se a importância de alguns, como Teixeira, Ribeiro Filho, Schmidt, Miranda, Martins, Walter, Espejo, Gonçalves, Jorge e Oliveira. Esses autores possuem alta centralidade de grau (degree), o que indica o maior número de relações na rede, ou seja, são aqueles que são mais procurados ou que procuram mais parceiros para a produção e publicação de artigos na REPeC, entre eles, Teixeira, Martins, Ribeiro Filho, Espejo e Walter aparecem como os mais profícuos deste estudo.

Ao se analisar a centralidade de intermediação (betweenness) na Figura 7, percebe-se a dispersão da rede, pois poucos atores representam essa medida - a maior parte encontra-se localizada no seu componente principal. Os autores Teixeira, Lustosa, Santos, Murcia, Beuren e Sousa são os maiores responsáveis pela troca da informação na rede. 


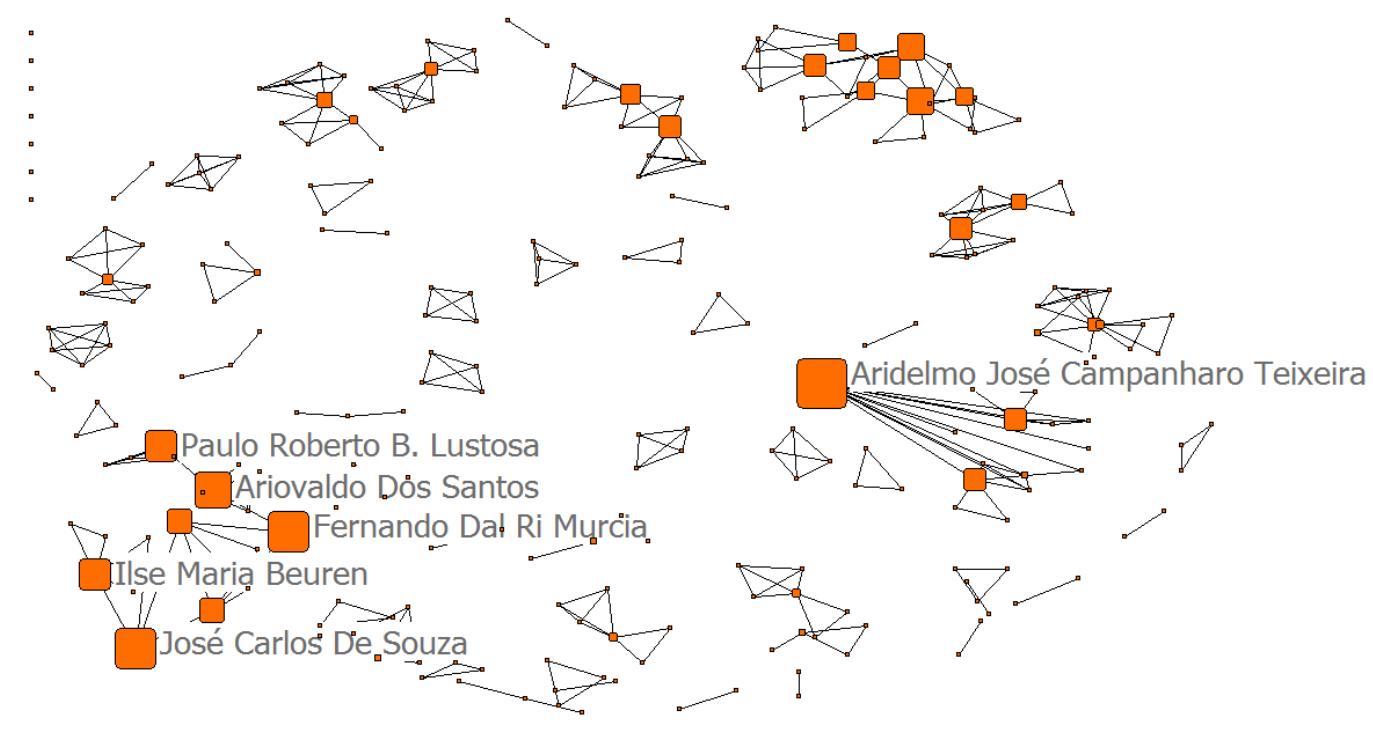

Figura 7. Rede de coautoria (betweenness)

Fonte: Dados da pesquisa

É interessante ressaltar que o autor Aridelmo José Campanharo Teixeira, além de ele ser o mais produtivo (Figura 4), é o que também possui alta centralidade de grau, assim como alta centralidade de intermediação neste estudo.

\subsection{Rede social das IES}

Já as Figura 8 e 9 apresentam as redes das 65 IES, sendo que a Figura 8 visualiza a centralidade de grau dessas IES e a Figura 9, a centralidade de intermediação. Além dessas figuras, exalta-se também a Figura 10, que trabalha uma rede two-mode (Latapy, Magnien \& Del Vecchio, 2008), evidenciando, nesse estudo, os dados originais das redes dos autores e das IES de maneira conjunta.

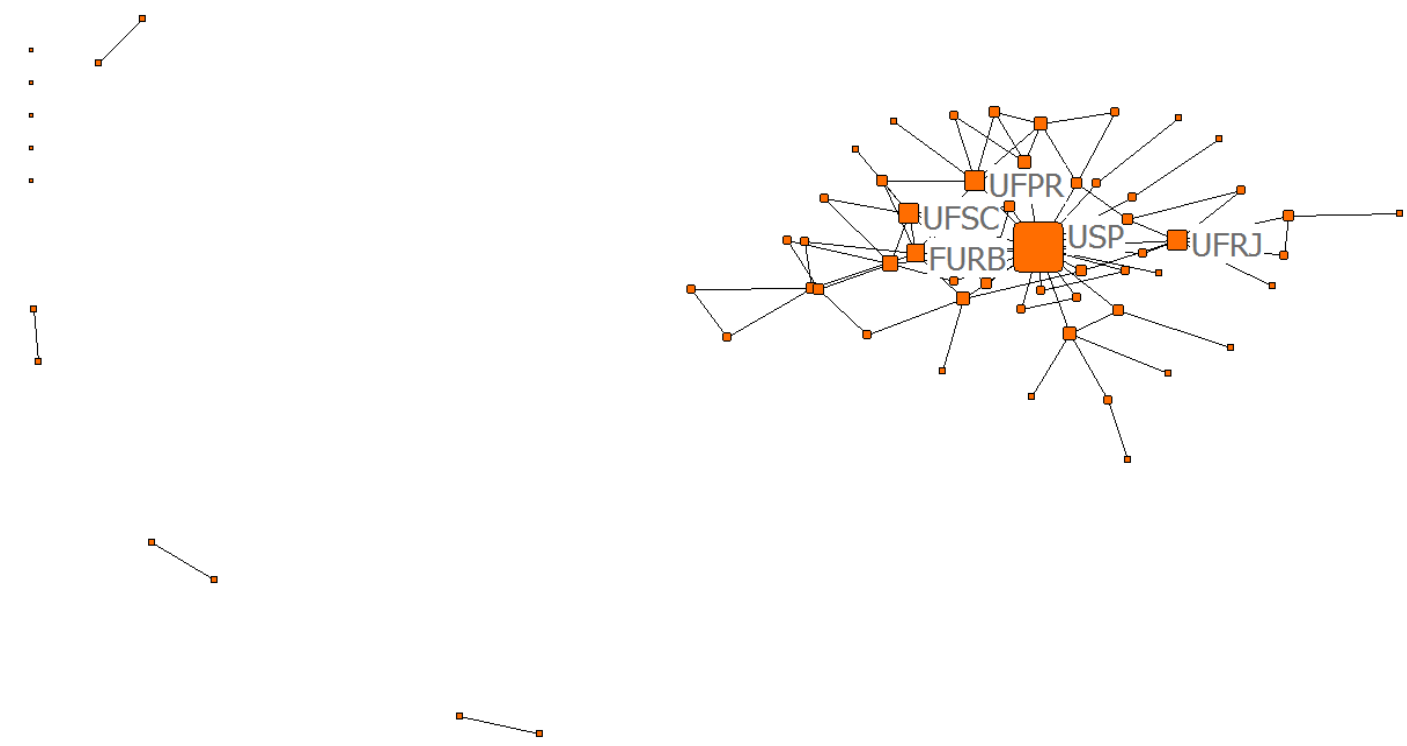

Figura 8. Rede social das IES (degree)

Fonte: Dados da pesquisa 
A Figura 8 concebe as cinco IES mais centrais deste estudo, no que se refere ao degree - USP, UFRJ, UFPR, UFSC e FURB, sendo que essas IES também figuram como algumas das que mais produziram artigos em seis anos de estudo. Ainda analisando-se a Figura 8, percebe-se sua centralidade, o que pode ser confirmado por sua densidade, que foi de 0,049 , ou seja, apenas $4,90 \%$ das relações estão sendo realizadas. Contudo, essa densidade de grau é superior ao que foi vista na rede de coautoria. Isso se justifica pela pouca quantidade de IES identificada e envolvida nessa pesquisa, o que resulta em uma maior interatividade entre elas.

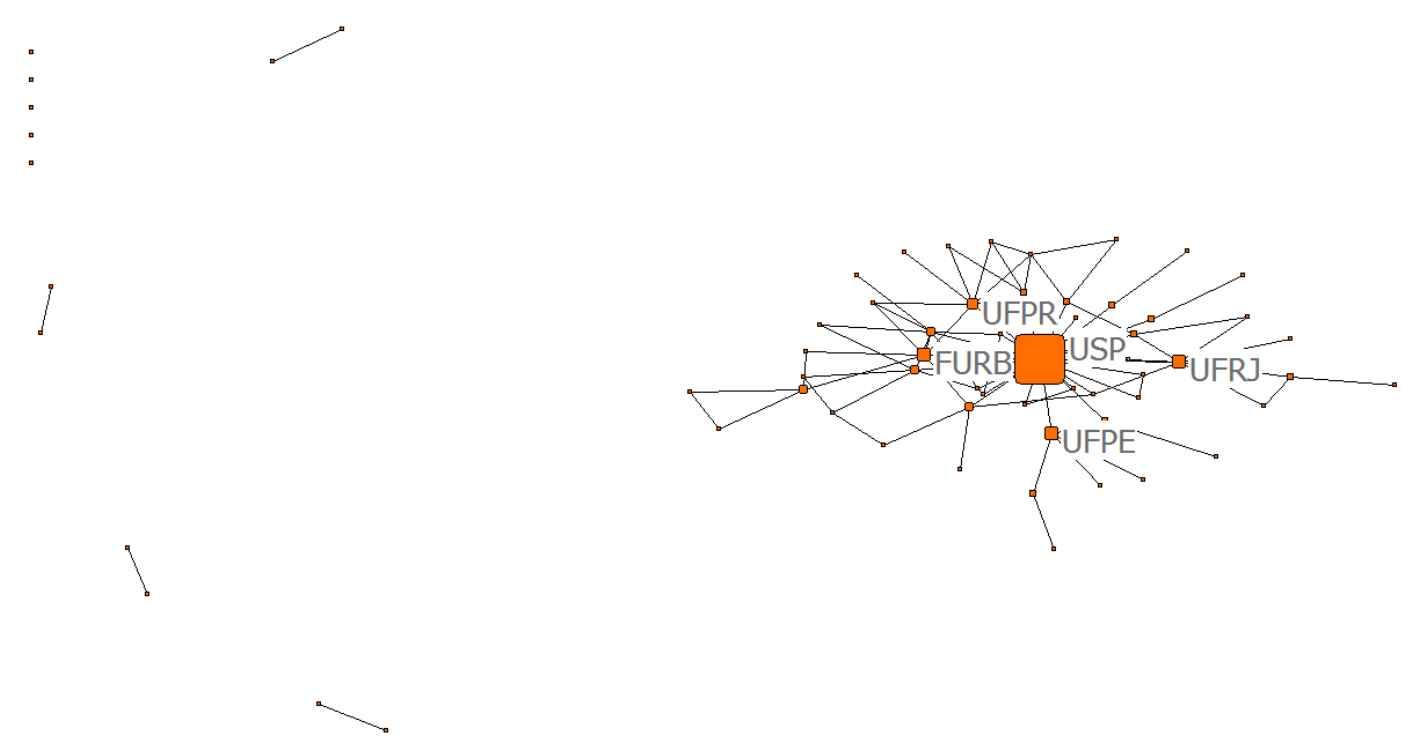

Figura 9. Rede social das IES (betweenness)

Fonte: Dados da pesquisa

Sabe-se que a medida de centralidade de intermediação é definida como a posição em que um ator está na rede, de modo a atuar como intermediador entre outros atores, ou seja, o ator (IES) se liga a vários outros que não possuem ligações diretas, isto é, considera o ator um meio para alcançar diversos outros atores (Hanneman \& Riddle, 2005). A Figura 9 realça as cinco IES com maior centralidade de intermediação neste trabalho, que foram: USP, UFRJ, UFPE, FURB e UFPR. Entre essas, destacam-se: USP, UFRJ, FURB e UFPR, pois, além de se destacarem como as IES com maior degree, também estão entre as 11 IES que mais produziram artigos neste estudo (Figura 5). 


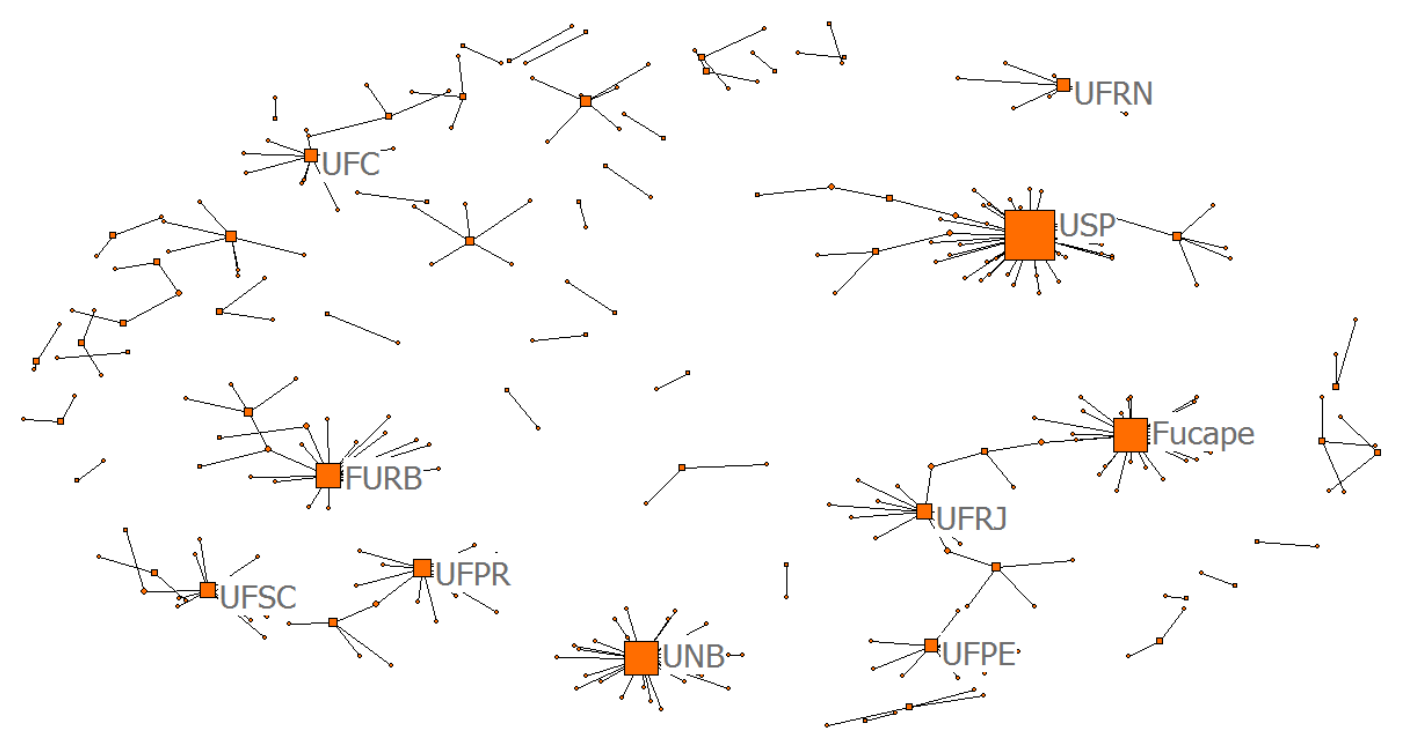

Figura 10. Centralidade de grau da rede social das IES com a rede social dos autores

Fonte: Dados da pesquisa

Já a Figura 10 junta as redes dos autores e das IES em uma two-mode. Constata-se que a USP, FUCAPE, UnB, FURB, UFPR, UFRJ, UFSC, UFRN, UFPE e UFC se destacaram nessa pesquisa. É importante realçar que das 10 IES realçadas na Figura 10 todas elas aparecem como as que mais publicaram artigos na REPeC. Entre essas 10, destaca-se a USP, indo ao encontro do que foi reportado nas Figuras 8 e 9, considerando-se assim a mais importante deste trabalho.

\subsection{Frequência das palavras-chaves}

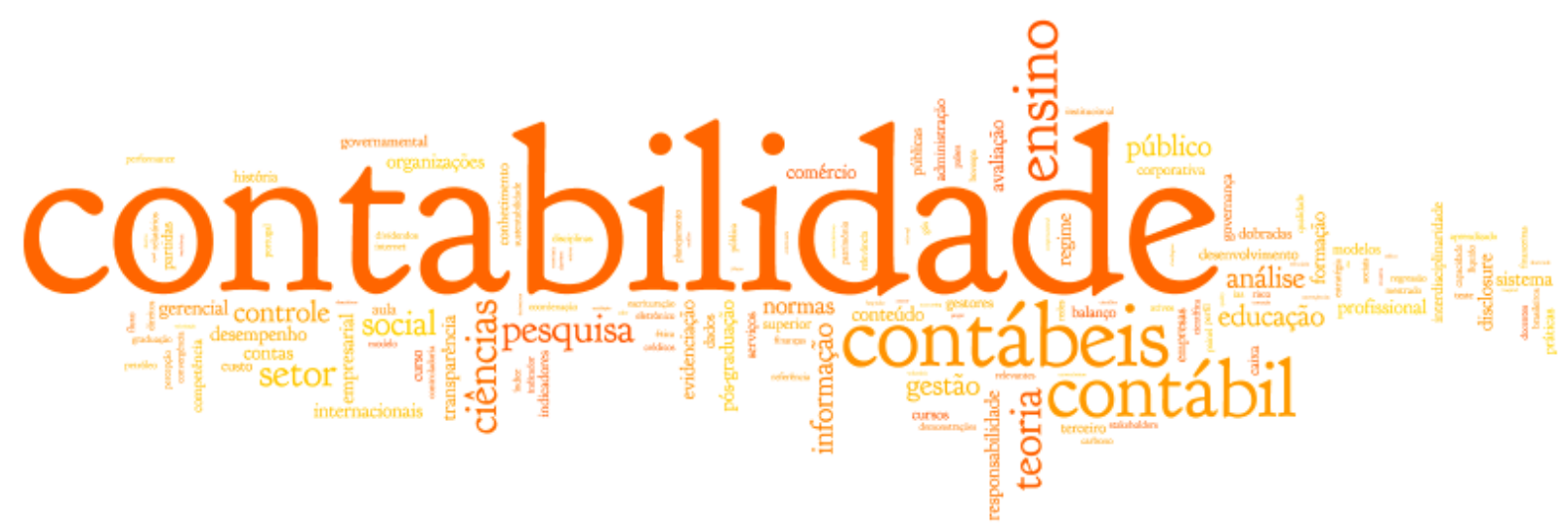

Figura 11. Frequência das palavras-chaves: no título e nas palavras-chaves

Fonte: Dados da pesquisa

Ressalta-se que a nuvem das palavras-chave é uma forma de visualização de dados linguísticos que mostra a frequência com que as palavras aparecem em determinado contexto (Francisco, 2011). Sendo assim, ficam destacadas as palavras-chaves: contabilidade, contábeis, contábil, ensino, ciências, pesquisa, entre outras. Remete-se à Lei de Zipf, que calcula a frequência de ocorrências das palavras, com o intuito de criar e evidenciar o tema científico que é mais contemplado nas pesquisas (Egghe, 2005). 


\subsection{Temas abordados}

A Tabela 1 contempla os 45 temas abordados nos 106 artigos investigados neste estudo.

Tabela 1.

\section{Temas abordados}

\begin{tabular}{|c|c|c|c|c|c|c|c|c|}
\hline Temas/Ano & 2007 & 2008 & 2009 & 2010 & 2011 & 2012 & Total & $\%$ \\
\hline Ensino e Pesquisa & 1 & 1 & 3 & & 3 & 2 & 10 & 9,43 \\
\hline Disclosure (Transparência) & & 2 & 2 & 2 & & 1 & 7 & 6,60 \\
\hline Contabilidade Internacional & & & & 1 & 2 & 4 & 7 & 6,60 \\
\hline Educação Contábil & 1 & & & 3 & 1 & & 5 & 4,72 \\
\hline Demonstrações Contábil-Financeira & 2 & 1 & & & & 2 & 5 & 4,72 \\
\hline Contabilidade Gerencial & 1 & 1 & & & 2 & 1 & 5 & 4,72 \\
\hline História da Contabilidade & & & & 1 & 3 & 1 & 5 & 4,72 \\
\hline Contabilidade Governamental & 1 & & 1 & 1 & & 1 & 4 & 3,77 \\
\hline Mercado de Capitais & & & 1 & & & 3 & 4 & 3,77 \\
\hline Controladoria & 1 & & 1 & & 1 & & 3 & 2,83 \\
\hline Ensino Superior & & 1 & 1 & & & & 2 & 1,89 \\
\hline Instituições Financeiras & 1 & & & & & 1 & 2 & 1,89 \\
\hline Balanço Social & 1 & & & & 1 & & 2 & 1,89 \\
\hline Desempenho Organizacional & 1 & & 1 & & & & 2 & 1,89 \\
\hline Análise de Risco & 1 & & & & 1 & & 2 & 1,89 \\
\hline Accountability (Prestação de Contas) & 1 & 1 & & & & & 2 & 1,89 \\
\hline Terceiro Setor & & 2 & & & & & 2 & 1,89 \\
\hline Governança Corporativa & & 1 & & & 1 & & 2 & 1,89 \\
\hline Gestão Ambiental & & 1 & & & & 1 & 2 & 1,89 \\
\hline Capital Intelectual & & & 2 & & & & 2 & 1,89 \\
\hline Estratégia & & & & 1 & 1 & & 2 & 1,89 \\
\hline Contabilidade de Custos & & & & 1 & & 1 & 2 & 1,89 \\
\hline Responsabilidade Social & & & & 1 & & 1 & 2 & 1,89 \\
\hline Indicadores Econômico-Financeiro & & & & 1 & & 1 & 2 & 1,89 \\
\hline Ética & & & & & 1 & 1 & 2 & 1,89 \\
\hline Profissional Contábil & & 1 & & & & 1 & 2 & 1,89 \\
\hline Crescimento Empresarial & 1 & & & & & & 1 & 0,94 \\
\hline Contabilidade Social & 1 & & & & & & 1 & 0,94 \\
\hline Princípios Contábeis & 1 & & & & & & 1 & 0,94 \\
\hline ISE & & 1 & & & & & 1 & 0,94 \\
\hline Auditoria & & 1 & & & & & 1 & 0,94 \\
\hline Ativo Intangível & & 1 & & & & & 1 & 0,94 \\
\hline Conservadorismo Contábil & & & 1 & & & & 1 & 0,94 \\
\hline Tecnologia da Informação & & & 1 & & & & 1 & 0,94 \\
\hline Contabilidade Introdutória & & & 1 & & & & 1 & 0,94 \\
\hline Organizações Esportivas & & & & 1 & & & 1 & 0,94 \\
\hline Ganhos de Valor & & & & 1 & & & 1 & 0,94 \\
\hline Administração Pública & & & & 1 & & & 1 & 0,94 \\
\hline Planejamento Organizacional & & & & & 1 & & 1 & 0,94 \\
\hline SPED & & & & & 1 & & 1 & 0,94 \\
\hline Organizações Contábeis & & & & & 1 & & 1 & 0,94 \\
\hline Perícia & & & & & 1 & & 1 & 0,94 \\
\hline Controle Patrimonial & & & & & 1 & & 1 & 0,94 \\
\hline Empreendedorismo & & & & & & 1 & 1 & 0,94 \\
\hline Teoria da Contabilidade & & & & & & 1 & 1 & 0,94 \\
\hline Total & 15 & 15 & 15 & 15 & 22 & 24 & 106 & 100,00 \\
\hline
\end{tabular}

Fonte: Dados da pesquisa 
A Tabela 1 evidencia os seguintes temas como os que mais foram trabalhados pelos autores neste estudo: Ensino e Pesquisa, Disclosure (transparência), Contabilidade Internacional, Educação Contábil, Demonstrações Contábil-Financeira, Contabilidade Gerencial, História da Contabilidade, Contabilidade Governamental, Mercado de Capitais e Controladoria. Os estudos de Perdigão, Niyama e Santana (2010), Brunozi Júnior et al. (2011) e Ribeiro (2012) corroboram, em parte, essas informações.

Em relação ao tema Ensino e Pesquisa, a abordagem mais trabalhada foi a pesquisa bibliométrica em artigos de congressos e periódicos. Entre os congressos mais trabalhados nesse tema foram o da ANPAD, Congresso USP de Controladoria e Contabilidade e ANPCONT.

Já as temáticas Disclosure e Contabilidade Internacional são assuntos importantes no cenário nacional e internacional (Perdigão, Niyama \& Santana, 2010) e a REPeC é um periódico da área contábil que, ao divulgar trabalhos sobre essas temáticas, auxilia na disseminação do conhecimento desses assuntos, incentivando o crescimento desses temas na área contábil, por entender que se encontram em evidência nos âmbitos corporativo e acadêmico (Perdigão, Niyama \& Santana, 2010). Remete ao fato de que Disclosure é considerado um dos princípios mais importantes da governança corporativa, além de ser um mecanismo responsável também por fomentar o desempenho da contabilidade internacional nas organizações (Szüster, Szüster \& Szüster, 2005), em especial aquelas que negociam suas ações em bolsa de valores (Santos \& Costa, 2008).

Realça-se a temática Demonstrações Contábil-Financeira e esta com o tema Contabilidade Internacional e, por que não dizer, também, com o assunto Disclosure, pois as demonstrações consolidadas podem ser consideradas marcos para a harmonização contábil internacional, evidenciando, com maior Disclosure, as informações contábil-financeira (Ikuno, Niyama, Santana \& Botelho, 2012) mitigando os riscos dos investidores em aplicar seu capital nas organizações que adotam essas boas práticas (Oliveira \& Lemes, 2011).

É significativo ressaltar que os temas mais abordados, vistos na Tabela 1, vão ao encontro das palavras-chaves mais visualizadas na Figura 11, mostrando uma relação forte entre esses indicadores analisados neste estudo e a Lei de Zipf (Egghe, 2005).

Ressalva-se também que só foram publicados uma vez cada um neste estudo os seguintes temas: Crescimento Empresarial, Contabilidade Social, Princípios Contábeis, Índice de Sustentabilidade Empresarial (ISE), Auditoria, Ativo Intangível, Conservadorismo Contábil, Tecnologia da Informação, Contabilidade Introdutória, Organizações Esportivas, Ganhos de Valor, Administração Pública, Planejamento Organizacional, Sistema Público de Escrituração Digital (SPED), Organizações Contábeis, Perícia, Controle Patrimonial, Empreendedorismo e Teoria da Contabilidade.

\subsection{Abordagens e métodos de pesquisa}

Por fim, as Figuras 12 e 13 evidenciam simultaneamente as abordagens e as técnicas de coleta e análise de dados trabalhados nos 106 artigos investigados neste estudo. 


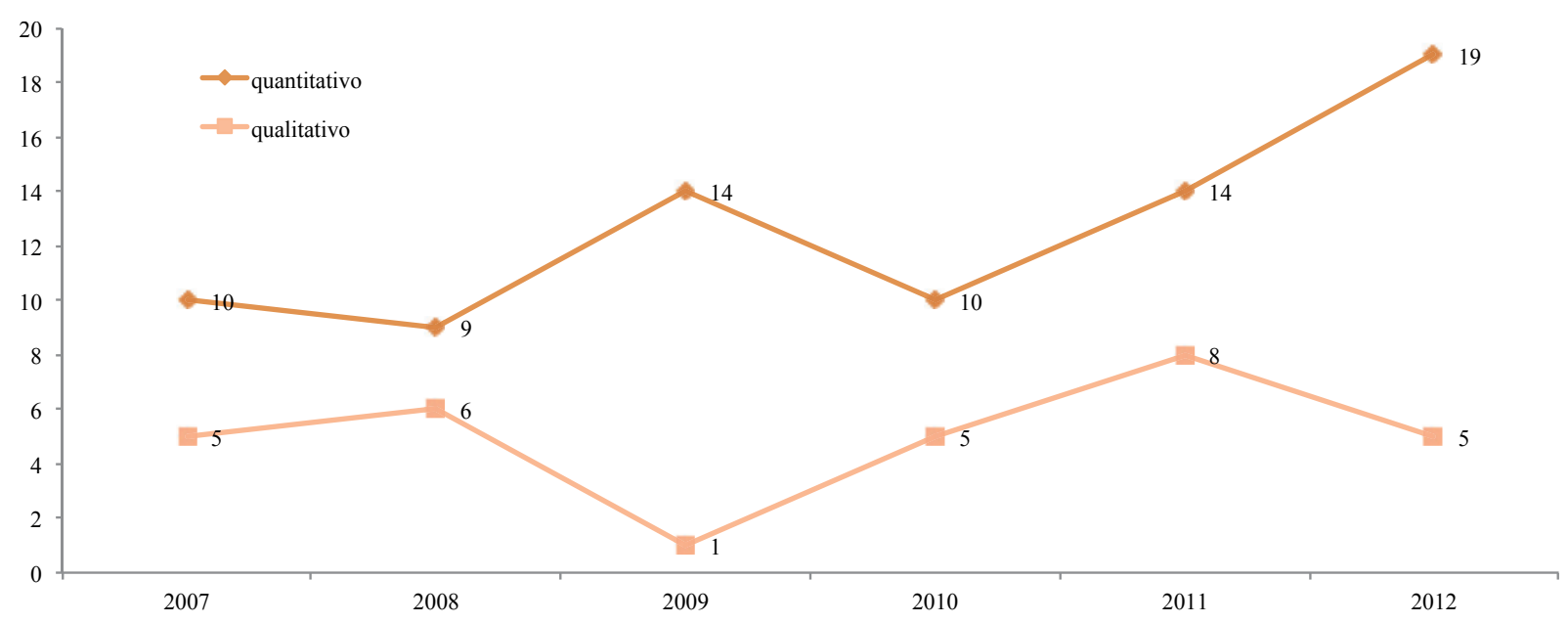

Figura 12. Abordagens de pesquisa

Fonte: Dados da pesquisa

\section{estatísticadescritiva \\ pesquisabibliográfica

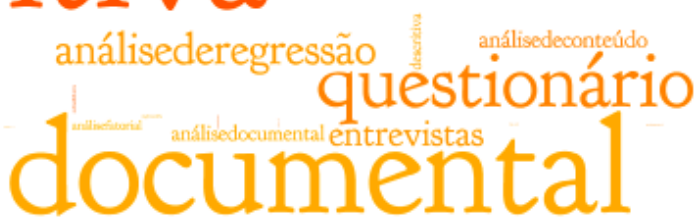

Figura 13. Métodos de pesquisa

Fonte: Dados da pesquisa

Analisando-se a Figura 12, constata-se que a abordagem quantitativa é predominante nos 106 investigados, alcançando seu ápice em 2012. Complementando a Figura 12, tem-se a Figura 13, que aborda as técnicas de coleta e análise de dados adotadas pelos 256 autores deste estudo. Os estudos dos pesquisadores Espejo et al. (2009a), Silva, Wanderley e Santos (2010), Dantas et al. (2011) e Ribeiro 2012 confirmam a tendência e a relação forte dos métodos quantitativos com área contábil.

Observa-se que as técnicas de coleta de dados predominantes foram o questionário e a pesquisa documental. A estatística descritiva foi a técnica de análise de dados mais utilizada entre os pesquisadores, seguida das estatísticas multivariadas, a análise de correlação e a análise de regressão.

\section{Considerações Finais}

O referido estudo explorou a produção acadêmica da Revista de Educação e Pesquisa em Contabilidade de 2007 a 2012. Para tanto, utilizou-se de técnicas de análise bibliométrica, como também da análise de redes sociais. Foram identificados 106 artigos em seis anos de estudo e usados os seguintes indicadores: (I) características de autoria; (II) autores com maior produção; (III) IES com maior produção; (IV) redes de coautoria; (V) rede social das IES; (VI) frequência das palavras-chave; (VII) temas abordados; e (VIII) abordagens e métodos de pesquisa para responder à questão de pesquisa que tracejou este estudo.

Constatou-se que a maioria dos artigos publicados é em parceria de, no mínimo, dois autores, ou seja, 90,57\% dos 106 artigos. Observou-se também que os autores Aridelmo José Campanharo Teixeira e Gilberto de Andrade Martins são os pesquisadores mais profícuos, com cinco e quatro artigos publicados, 
respectivamente. Entre esses autores, destaca-se Aridelmo José Campanharo Teixeira como o pesquisador mais central deste estudo, tanto no que tange à centralidade de grau como também à centralidade de intermediação. A Universidade de São Paulo é a IES que mais publicou artigos nesses seis anos de pesquisa, sendo também considerada a IES com maior centralidade de grau e de intermediação neste estudo.

No entanto, é bom ressaltar a diversidade de autores (256) e IES (65) envolvidos na publicação dos 106 artigos estudados em seis anos de pesquisa. Esse número elevado de autores e IES é preponderante e inerente aos periódicos que se preocupam com a busca pela diversificação e socialização de opiniões e pontos de vista.

Evidenciou-se que os temas Ensino e Pesquisa, Disclosure (transparência), Contabilidade Internacional, Educação Contábil, Demonstrações Contábil-Financeira, Contabilidade Gerencial, História da Contabilidade, Contabilidade Governamental, Mercado de Capitais e Controladoria foram os que se destacaram na temporalidade de seis anos de pesquisa, representando 51,89\% do total dos 106 artigos analisados. Tal dado vai ao encontro das principais palavras-chaves visualizadas nesses artigos, que foram: contabilidade, contábeis, contábil, ensino, ciências e pesquisa.

O objetivo proposto no estudo foi alcançado, além de apresentar uma agenda para pesquisa sobre Educação e Pesquisa em Contabilidade sob a ótica da REPeC, com base nos 106 trabalhos identificados. Outra contribuição é do avanço e aperfeiçoamento dos papers sobre educação e pesquisa em contabilidade no meio acadêmico. Salienta-se que os achados deste estudo contribuirão na emergência, disseminação e otimização dos temas ora investigados para a literatura acadêmica nacional, proporcionando, a posteriori, a possibilidade de surgimento e aperfeiçoamento de grupos de pesquisa que possibilitaram uma melhor reflexão sobre esses temas.

Conclui-se, de maneira geral, que o acervo da Revista de Educação e Pesquisa em Contabilidade reflete o universo da produção acadêmica da área contábil, ajudando assim a desenvolver, disseminar e socializar a área por meio de artigos científicos publicados na literatura acadêmica nacional.

Entende-se como fator limitador desta pesquisa o aperfeiçoamento dos métodos de pesquisa trabalhados neste estudo, como, por exemplo, otimizar a abordagem quantitativa de dados por meio da utilização da análise multivariada de dados, por exemplo, que poderia assim fomentar as informações aqui evidenciadas, em especial os dados bibliométricos. E assim sugere-se uma otimização das técnicas de análise bibliométrica. Sugere-se também um aperfeiçoamento da análise de redes, trabalhando a centralidade de proximidade (Closeness), como também os nós e laços dos autores de maneira individual e consolidada. Também sugere-se uma análise de conteúdo dos 45 temas identificados e divulgados neste estudo.

\section{Referências}

Balestrin, A., Verschoore, J. R., \& Reyes Junior, E. (2010). O campo de estudo sobre redes de cooperação interorganizacional no Brasil. Revista de Administração Contemporânea, 14(3), 458-477.

Barbosa, E. T., Echternacht, T. H. de S., Ferreira, D. L., \& Lucena, W. G. L. (2008). Uma análise bibliométrica da Revista Brasileira de Contabilidade no período de 2003 a 2006. In: CONGRESSO USP DE CONTROLADORIA E CONTABILIDADE. VIII CONGRESSOUSP. Anais Eletrônicos... Rio de Janeiro: CONGRESSOUSP. Recuperado em 10 março, 2013 de <http://www.congressousp.fipecafi.org/artigos82008/618.pdf>.

Batistella, F. D., Bonacim, C. A. G., \& Martins, G. de A. (2008). Contrastando as produções da Revista Contabilidade \& Finanças (FEA-USP) e Revista Base (Unisinos). Revista de Educação e Pesquisa em Contabilidade, 2(3), 84-101.

Beuren, I. M., \& Longaray, A. A. (2003). Como elaborar trabalhos monográficos em contabilidade: teoria e prática. São Paulo: Atlas. 
Brunozi Júnior, A. C., Emmendoerfer, M. L., Abrantes, L. A., \& Klein, T. C. (2011). Revista Contabilidade \& Finanças - USP: uma análise do perfil da produção científica de 1989 a 2009. Revista Universo Contábil, 7(4), 39-59.

Cabral, I., Siqueira, J. R. M. de, \& Siqueira-Batista, R. (2011). O diálogo das ciências contábeis com as ciências humanas e demais ciências sociais: uma análise da produção acadêmica do Congresso USP de Controladoria e Contabilidade Enanpad (2004-2007). Revista de Educação e Pesquisa em Contabilidade, 5(4), 100-125.

Capes. (2013). Webqualis. Recuperado em 10 março, 2013 de < http://qualis.capes.gov.br/webqualis/publico/pesquisaPublicaClassificacao.seam;jsessionid=05485DB28249C1FFBA8A81F0E312902A. qualismodcluster-node-66>.

Cardoso, R. L., Neto, O. R. de M., Riccio, E. L., \& Sakata, M. C. G. (2005). Pesquisa científica em contabilidade entre 1990 e 2003. Revista de Administração de Empresas, 45(2), 34-45.

Chambers, E. A. (2004). An introduction to meta-analysis with articles from the journal of educational research (1992-2002). The Journal of Educational Research, 98(1), 35-44.

Coelho, A. C., Soutes, D. O., \& Martins, G. de A. (2010). Abordagens metodológicas na área "contabilidade para usuários externos" - Enanpad: 2005-2006. Revista de Educação e Pesquisa em Contabilidade, 4(1), 18-37.

Cruz, A. P. C. da, Espejo, M. M. dos S. B., Costa, F., \& Almeida, L. B. de. (2011). Perfil das redes de cooperação científica: Congresso USP de controladoria e contabilidade - 2001 a 2009. Revista Contabilidade \& Finanças, 22(55), 64-87.

Dantas, J. A., Silva, C. A. T., Santana, C. M., \& Vieira, E. T. (2011). Padrões de comunicação científica em contabilidade: um comparativo entre a Revista Contabilidade e Finanças e a The Accounting Review. Revista Contemporânea de Contabilidade, 8(16), 11-36.

Demuner, J. A., Dias, V. L., Silva Junior, A. da, \& Pelissari, A. S. (2008). Coordenação e controle nos Enanpads de 1998 a 2005: em busca da pesquisa positiva. Revista de Educação e Pesquisa em Contabilidade, 2(3), 1-15.

Dias, W. de O., Barbosa Neto, J. E., \& Cunha, J. V. A. da. (2011). A comunicação do conhecimento científico: dados sobre a celeridade do processo de avaliação e de publicação de artigos científicos em periódicos da área de contabilidade. Revista Contemporânea de Contabilidade, 8(15), 41-62.

Didriksson, A. (2003). La sociedad del conocimiento desde la perspectiva latinoamericana. Memorias Del IV Encuentro de Estudios Prospectivos Región Andina: Sociedad, Educación y Desarrollo: Medellín.

Egghe, L. (2005). Zipfian and lotkaian continuous concentration theory. Journal of the American Society for Information Science and Technology, 56(9), 935-945.

Espejo, M. M. dos S. B., Cruz, A. P. C. da, Lourenço, R. L., Antonovz, T., \& Almeida, L. B. de. (2009). Estado da arte da pesquisa contábil: um estudo bibliométrico de periódicos nacional e internacionalmente veiculados entre 2003 e 2007. Revista de Informação Contábil, 3(3), 94-116.

Espejo, M. M. dos S. B., Cruz, A. P. C. da, Walter, S. A., \& Gassner, F. P. (2009). Campo de pesquisa em contabilidade: uma análise de redes sob a perspectiva institucional. Revista de Educação e Pesquisa em Contabilidade, 3(2), 45-71.

Ferreira, M. P. (2011). A bibliometric study on ghoshal's managing across borders. The Multinational Business Review, 19(4), 357-375.

Francisco, E. de R. (2011). RAE-eletrônica: exploração do acervo à luz da bibliometria, geoanálise e redes sociais. Revista de Administração de Empresas, 51(3), 280-306. 
Freeman, L. C. (1992). Social networks and the structure experiment. In: L. C. Freeman, D. R.; White; K. A. Romney (Eds.). Research methods in social network analysis. (pp. 11-40). New Brunswick, NJ: Transaction Publishers.

Freitas, E. M., Pacheco, V., Karolkievicz, R. M., \& Sillas, E. P. (2012). Cooperação acadêmica: análise de publicações em eventos científicos sobre ensino e pesquisa em contabilidade. Revista de Educação e Pesquisa em Contabilidade, 6(4), 399-418.

Gnyawali, D., \& Madhavan, R. (2001). Cooperative networks and competitive dynamics: a sctrutural embeddedness perspective. Academy of Management Review, 26(3), 431-445.

Gonzalo, O. M., Hernández, A; Hernández C. y Mendes, C. (2009). Análisis bibliométrico de la revista de economía institucional en sus primeros diez años. Revista de Economía Institucional, 11(20), 309-353.

Guarido Filho, E. R., Machado-da-Silva, C. L., \& Gonçalves, S. A. (2009). Organizational institutionalism in the academic field in Brazil: social dynamics and networks. Brazilian Administration Review, 6(4), 299-315.

Guarido Filho, E. R., \& Machado-da-Silva, C. L. (2010). The development of institutional theory in the field of organization studies in Brazil. Cadernos EBAPE.BR, 8(2), 279-301.

Hanneman, R. A., \& Riddle, M. (2005). Introduction to Social Network Methods. Riverside: University of California.

Ikuno, L. M., Niyama, J. K., Santana, C. M., \& Botelho, D. R. (2012). Contabilidade internacional: uma análise da produção científica nos principais periódicos internacionais da área - 2000 a 2009. Revista de Contabilidade e Organizações, 6(15), 142-163.

Latapy, M., Magnien, C., \& Del Vecchio, N. (2008). Basic notions for the analysis of large two-mode networks. Social Networks, 30(1), 31-48.

Leite Filho, G. A., \& Siqueira, R. L. (2007). Revista Contabilidade \& Finanças USP: uma análise bibliométrica de 1999 a 2006. Revista de Informação Contábil, 1(2), 102-119.

Martins, G. de A. (2007). Avaliação das avaliações de textos científicos sobre contabilidade e controladoria. Revista de Educação e Pesquisa em Contabilidade, 1(1), 1-13.

Meli, D. B., \& Oliveira Neto, J. D. de. (2011). O perfil da colaboração nos periódicos contábeis nacionais: muitos one-timers e poucos continuants. Revista Contemporânea de Contabilidade, 8(15), 151-176.

Moreira, O., Riccio, E. L., \& Sakata, M. C. G. (2007). A comunicação de informações nas instituições públicas e privadas: o caso XBRL extensible business reporting language in Brazil. Revista de Administração Pública, 41(4), 769-784.

Nerur, S. P., Rasheed, A. A., \& Natarajan, V. (2008). The intellectual structure of the strategic management field: an author co-citation analysis. Strategic Management Journal, 29, 319-336.

Olak, P. A., Slomski, V., \& Alves, C. V. O. (2008). As publicações acadêmicas da pesquisa contábil no Brasil, no âmbito das organizações do terceiro setor. Revista de Educação e Pesquisa em Contabilidade, 2(1), 24-46.

Oliveira, M. C. (2002). Análise dos periódicos brasileiros de contabilidade. Revista Contabilidade \& Finanças, 13(29), 68-86.

Oliveira, V. A., \& Lemes, S. (2011). Nível de convergência dos princípios contábeis brasileiros e norte-americanos às normas do IASB: uma contribuição para a adoção das IFRS por empresas brasileiras. Revista Contabilidade \& Finanças, 22(56), 155-173.

Perdigão, L. Z., Niyama, J. K., \& Santana, C. M. (2010). Contabilidade, gestão e governança: análise de doze anos de publicação (1998 a 2009). Contabilidade, Gestão e Governança, 13(3), 3-16. 
Ramos-Rodríguez, A. R., \& Ruíz-Navarro, J. (2004). Changes in the intellectual structure of strategic management research: a bibliometric study of the strategic management journal, 1980-2000. Strategic Management Journal, 25, 981-1004.

Revista de Educação e Pesquisa em Contabilidade - REPeC. (2013). Foco e escopo. Recuperado em 10 março, $2013 \mathrm{de}<\mathrm{http}$ //www.repec.org.br/index.php/repec/about/editorialPolicies\#focusAndScope>.

Revista de Educação e Pesquisa em Contabilidade - REPeC. (2013). Notícias. Recuperado em 10 março, 2013 de < http://www.repec.org.br/index.php/repec/index>.

Ribeiro, H. C. M. (2012). Brazilian Business Review: um estudo sob a ótica da bibliometria e da rede social de 2004 a 2011. Revista de Gestão, Finanças e Contabilidade, 2(3), 86-104.

Richardson, R. J., \& Peres, J. A. de S. (1989). Pesquisa social: métodos e técnicas. São Paulo: Atlas.

Rossoni, L., Hocayen-da-Silva, A. J., \& Júnior, I. F. (2008). Aspectos estruturais da cooperação entre pesquisadores no campo de administração pública e gestão social: análise das redes entre instituições no Brasil. Revista de Administração Pública, 42(6), 1041-1067.

Rowe, D. E. O., \& Bastos, A. V. B. (2010). Vínculos com a carreira e produção acadêmica: comparando docentes de IESs públicas e privadas. Revista de Administração Contemporânea, 14(6), 1011-1030.

Santos, L. S. R. dos, \& Costa, F. M. da. (2008). Conservadorismo contábil e timeliness: evidências empíricas nas demonstrações contábeis de empresas brasileiras com ADRs negociadas na bolsa de Nova Iorque. Revista Contabilidade \& Finanças, 19(48), 27-36.

Scott, J. (2000). Social network analysis: a handbook (2a ed.). London: SagePublications.

Sebastián, J. (1999). Analisis de las redes de investigacion de America Latina con la Unión Europea. Revista de Ciência e Tecnologia, 3(2), 308-321.

Silva, A. C. da, Wanderley, C. A. N., \& Santos, R. dos. (2010). Utilização de ferramentas estatísticas em artigos sobre contabilidade financeira - um estudo quantitativo em três congressos realizados no país. Revista Contemporânea de Contabilidade, 1(14), 11-28.

Silva, A. P. B. da, \& Ott, E. (2012). Um estudo sobre a interação entre a pesquisa científica e a prática profissional contábil. Revista de Educação e Pesquisa em Contabilidade, 6(2), 204-220.

Souza, F. J. V. de, Silva, M. C. da, Araújo, A. O., \& Silva, J. D. G. da. (2012). Revista de Contabilidade do Mestrado em Ciências Contábeis da UERJ: uma análise de oito anos de publicação (2003 a 2011). Revista de Administração, Contabilidade e Sustentabilidade, 2(3), 69-85.

Szüster, N., Szüster, F. R., \& Szüster, F. R. (2005). Contabilidade: atuais desafios e alternativa para seu melhor desempenho. Revista Contabilidade \& Finanças, 16(38), 20-30.

Tomaél, M. I., \& Marteleto, R. M. (2006). Redes sociais: posições dos atores no fluxo da informação. Revista Eletrônica de Biblioteconomia e Ciência da Informação, Especial, 75-91.

Wasserman, S., \& Faust, K. (1994). Social network analysis: methods and applications. Cambridge: Cambridge University Press. 